\section{Triagem Neonatal: Ficção ou Realidade?}

A Sociedade Brasileira de Endocrinologia e Metabologia (SBEM) foi a primeira sociedade médica a adotar medidas oficiais no sentido de estimular e organizar a triagem neonatal no Brasil, através da criação de uma Comissão de Programas de Rastreamento Neonatal, em 1990. Naquela época existiam poucos programas de triagem neonatal, destacando-se o pioneiro, implantado por Benjamin Schmidt, na APAE de São Paulo, e o da Fundação Ecumênica do Paraná. O Departamento de Endocrinologia da Escola Paulista de Medicina buscava alternativas menos dispendiosas que permitissem a realização das dosagens de TSH e tiroxina com tecnologia e papel de filtro nacionais (1), iniciando um programa próprio de rastreamento para o hipotiroidismo congênito.

Em 1989 realizara-se, no Rio de Janeiro, durante o III Simpósio Carioca de Tiróide, o primeiro Fórum de Debates sobre Screening Neonatal, sendo o segundo organizado, no mesmo ano, em Foz do Iguaçu, por ocasião do III Congresso Latino Americano de Endocrinologia Pediátrica. Depois desses, a Comissão de Programas de Rastreamento Neonatal promoveu mais oito fóruns de debates, ao longo dos últimos dez anos, atraindo uma audiência cada vez maior e mais participante. As discussões realizadas nos fóruns forneceram subsídios para a regulamentação das leis, já existentes, que estabeleciam a obrigatoriedade do diagnóstico do hipotiroidismo congênito e fenilcetonúria (2).

Novos pólos de rastreamento neonatal foram criados $\mathrm{cm}$ todo o país. Entre 1995 e 1999 o número total de exames realizados anualmente na rede pública de saúde brasileira cresceu de 1,3 para 1,8 milhões (fonte: Datasus - http://www.datasus.gov.br/cgi/sia/pamap.htm). As entidades filantrópicas ainda são responsáveis pela maioria dos testes, mas a participação das Secretarias de Estado de Saúde vem aumentando progressivamente, ocupando o segundo lugar em número de exames realizados, à frente das Universidades e das Secretarias Municipais de Saúde.

A multiplicação dos programas de rastreamento neonatal e suas características multidisciplinares indicavam a necessidade de uma sociedade específica para congregar os interessados. Em 18 de setembro de 1999 foi organizado pela Comissão de Programas de Rastreamento Neonatal o décimo e último Fórum de Debates sobre Screening Neonatal, na cidade de São Paulo, em que se decidiu a criação da Sociedade Brasileira de Triagem Neonatal (SBTN), concretizada em $l^{\underline{9}}$ de abril de 2000. Nasce, assim, uma nova sociedade, filha, por assim dizer, da SBEM. Tem ela o compromisso de continuar e ampliar o trabalho iniciado pela Comissão de Programas de Rastreamento Neonatal da SBEM.

Muitos municípios ainda não fazem o "teste do pezinho". Não é fácil a implantação de um programa de triagem neonatal, mas a publicação das dificuldades observadas nos primeiros programas e das soluções encontradas auxiliam aos que se propõem a fazê-lo $(3,4)$. Uma vez implantado, é importante que o programa seja eficiente. A cobertura do programa deve ser total, ou seja, devem ser colhidas amostras para exame de todos os
Ricardo M. R. Meivelles

Presidente da Comissāo de Programas de Rastreamento Neonatal da Sociedade Brasileira de Endocrinologia e Metabologia 
recém-nascidos. O controle de qualidade das dosagens deve ser estrito e, se possível, realizado por órgãos independentes internacionais (por exemplo: Centers for Disease Control and Prevention e Association of Public Health Laboratories). Não basta fazer o diagnóstico da doença pesquisada. É preciso que o resultado do exame chegue às mãos do médico da criança no mais curto espaço de tempo possível, para permitir que a terapêutica seja instituída precocemente, única forma de evitar o déficit mental que o hipotiroidismo e a fenilcetonúria acarretam. Finalmente, é imprescindível que a rede pública de saúde garanta os meios para o tratamento das crianças diagnosticadas: consultas médicas e de nutricionistas, exames complementares para acompanhamento, hormônio tiroidiano e leite isento de fenilalanina.

Análises críticas como a publicada neste número dos Arquivos Brasileiros de Endocrinologia e Metabologia (5) são bem-vindas e necessárias. Nesse artigo, Ramalho e colaboradores apontam diversas inadequações de um programa de triagem para o hipotiroidismo congênito, à época em que foi analisado. A cobertura estava muito distante de contemplar a totalidade da população (apenas $42 \%$ na capital e absurdos 5\% nas cidades do interior). Metade das amostras eram colhidas com mais de quatro semanas de vida, idade em que, idealmente, o tratamento das crianças afetadas já deveria estar em curso. Além da demora para a coleta da amostra, foram identificados atrasos na chegada do resultado aos centros de saúde, à família e ao médico assistente. Como conseqüência, metade das crianças contavam mais de 72 dias de vida quando o teste de triagem foi visto pelo médico, ocasião em que os casos positivos certamente já teriam lesões neurológicas irreversíveis (6).

Outro aspecto salientado por Ramalho e colaboradores (5) foi a ausência de um mecanismo prioritário de referência das crianças com resultados anormais para serviços especializados. O ideal seria que o próprio programa de triagem neonatal oferecesse o tratamento integral aos bebês com hipotiroidismo congênito ou fenilcetonúria, obedecendo a rotinas estabelecidas, de modo a permitir avaliação permanente dos resultados. Quando isso não fosse possível, como no caso de residentes em locais distantes, essas rotinas poderiam ser enviadas ao médico assistente, se necessário com os recursos materiais para o tratamento (hormônio tiroidiano ou leite isento de fenilalani- na). Deveria também ser garantido um canal de comunicação através do qual os profissionais de saúde pudessem receber orientação e esclarecimentos sobre as peculiaridades dessas terapêuticas.

O último parágrafo do artigo de Ramalho e colaboradores (5) dá conta de como pode ser útil uma avaliação crítica como a realizada pelos autores, que resultou $\mathrm{em}$ providências objetivas para sanear os erros apontados. A experiência mundial já comprovou a utilidade da triagem neonatal. O Brasil já tem leis que obrigam a sua realização e a recém criada Socicdade Brasileira de Triagem Neonatal pode contribuir para a implementação e acompanhamento de novos programas. A vigilância para que esses programas sejam eficientes, entretanto, é fundamental. Pior do que não ter programas de triagem neonatal é tê-los ineficazes, pois estes geram uma falsa sensação de segurança, consomem recursos públicos e não contribuem para minimizar as graves conseqüências das doenças pretensamente rastreadas. Triagem neonatal deve ser uma realidade e não uma ficção.

\section{REFERÊNCIAS}

1. Menabó E, Vieira JGH, Russo EMK, Kunii IK, Miranda WL, Maciel RMB. Determinação da tirotrofina (TSH) em sangue total seco colhido em papel de filtro: desenvolvimento da metodologia e aplicação em programas de detecção precoce de hipotiroidismo congênito. Arq Bras Endocrinol Metabol 1990;34(2): 17-22.

2. Meirelles RMR, Maciel RMB, Machado-Filho A, Castro AS. Subsídios para regulamentação das leis que estabelecem a obrigatoriedade do diagnóstico do hipotiroidismo congênito e fenilcetonúria. Arq Bras Endocrinol Metabol 1991:35(1):12-14.

3. Botler J: Análise crítica da implantação de um programa de rastreamento para hipotiroidismo congênito no Estado do Rio de Janeiro. (Mestrado). Pontificia Universidade Católica; 1992.

4. Franco DB, Maciel RMB, Matsumura LK, Kunii is, Furuzawa GK, Faria AM, et al. Implantação do programa de rastreamento do hipotiroidismo congênito na Fundação Hospitalar do Distrito Federal: Metodologia, resultados, dificuldades e propostas. Estudo comparativo com recêm-natos de outros estados. Arq Bras Endocrinol Metabol 1997:41(1):6-13.

5. Ramalho RJR, Valido DP, Aguiar-Oliveira MH. Avaliação do programa de triagem para o hipotiroidismo congênito no estado de Sergipe. Arq Bras Endocrinol Metabol 2000;44(2): 157-61.

6. Botler J. Repercussões neurológicas do hipotiroidismo congênito. Arq Bras Endocrinol Metab 1996:40(4):264-70. 